\title{
Genetic Mechanisms and Biological Implications of Phase Variation in Pathogenic Neisseriae
}

\author{
THOMAS F. MEYER ${ }^{1 *}$ AND J. P. M. VAN PUTTEN ${ }^{2}$ \\ Max-Planck-Institut für Biologie, Infektgenetik, Spemannstrasse 34, D-7400 Tübingen, Federal Republic of Germany, ${ }^{1}$ \\ and Department of Medical Microbiology, University of Amsterdam, NL-1105 AZ \\ Amsterdam, The Netherlands ${ }^{2}$
}

A sophisticated strategy used by a number of procaryotic and eucaryotic microorganisms to escape host defense mechanisms is that of varying the expression of their major surface antigens. This immune escape strategy has been nicely documented for African trypanosomes (6) and Borrelia hermsii (2). Antigen variation in pathogenic neisseriae leads to another intriguing view of the same phenomenon: the variation of functional properties of the respective surface proteins. There are two classes of proteins in pathogenic neisseriae that undergo antigenic variation, (i) pilin, the major subunit of the pili, and (ii) the opacity-associated proteins (OPAs), previously P.II or class 5 proteins, a family of heat-modifiable outer membrane proteins. Both classes of proteins are substantially immunogenic and have an essential role in bacterial adherence. Conceivably, variation of these proteins not only leads to immunological changes but also gives rise to alterations of their functional (i.e., adhesive) properties. Although little is known about the biological role of antigen variation in Neisseria species, extensive molecular genetic investigations performed during the past several years might lead us to gain better insight into this field.

\section{GENETICS OF SURFACE PROTEIN VARIATION}

\section{Primary Structure of Pilin and Organization of Pilin Genes}

Variation of pilin expression in gonococci relies on a multigene system. The genetics of this system have been studied in greatest detail for Neisseria gonorrhoeae MS11 (3, $33)$; complementary work has been done with $N$. gonorrhoeae $\mathrm{P} 9$ and $N$. meningitidis $\mathrm{C} 114(35,36)$. The gonococcal genome usually contains a single structural gene that is responsible for pilin expression (pilE); however, two expressed genes are occasionally found $(31,33)$. The pilE locus codes for the production of a pilin precursor (propilin) that carries a seven-amino-acid transport signal at its amino terminus. Posttranslational processing of propilin involves replacement of the short signal peptide by an $\mathrm{N}$-methyl group (21). The signal peptide is linked to an adjacent hydrophobic region which constitutes the amino terminus of mature pilin. Functionally, this hydrophobic region is thought to substitute for the hydrophobic core, typically seen in transport signals but missing in the short signal of propilin. Furthermore, this region has been implicated in the polymerization of pilin into pili. The amino-terminal portion of pilin is conserved among different gonococcal pilin molecules and shows homology with the $\mathrm{N}$-methyl pili of related species (see, e.g., reference 39 ).

Almost all variations between different gonococcal pilins seem to occur within six short regions, called minicassettes

\footnotetext{
* Corresponding author.
}

(MCs), located toward the central and carboxy-terminal portions of pilin $(14,15,54)$. Of all the minicassettes, MC2 is the most variable and constitutes the immunodominant region of pilin. The short sequences interspersed between the MCs are highly conserved at both the protein and deoxyribonucleic acid (DNA) levels of variant genes (14).

In addition to the expression gene(s), a gonococcal cell contains many silent gene loci (pilS). A silent locus carries one or more partial pilin gene copies which are tandemly arranged and connected by repetitive sequences (13). Although these partial gene copies show the same arrangement of variable MCs in comparison with variant expression genes, they are devoid of the conserved amino-terminal coding sequences (13). Silent loci carry several repetitive sequence motifs with counterparts in the expression loci (13). Striking sequence homologies and similarities in the organization of silent and expressed genes are observed between gonococci and meningococci (36).

\section{Variation of Pilin Expression}

Changes in the expression of pilin result from recombination of silent gene copies with the expressed gene. In this way, the expressed gene acquires variable minicassettes such that some, but not all, of its minicassettes are replaced by minicassettes from any of the silent loci. This intragenic recombination leads to an immense variability of sequences in the expression genes $(14,15,54)$.

Most often, variant propilins produced by an altered expression gene give rise to pili with altered antigenic and adhesive properties $(28,58)$. Some propilins, however, are processed in an alternative fashion at position 40 (Fig. 1). This alternative cleavage, which seems to depend on the sequence composition in the expressed gene, removes the hydrophobic region of pilin. Consequently, the resulting product (called $S$ pilin) is unable to polymerize; $S$ pilin is instead secreted as a soluble antigen (14). If all the propilin is converted into $S$ pilin, the host cells are of course nonpiliated. Often, though, the propilin of $S$ variants is only partially converted into $S$ pilin, thus giving rise to cells which show weak or intermediate piliation and which produce standard pilin and $S$ pilin at the same time.

Recombination between cassettes of the pilS6 locus and pilE leads to yet another type of variant ( $\mathrm{L}$ variant) that is characterized by a slightly extended expression locus (P. A. Manning, T. F. Meyer, A. Kaufmann, B.-Y. Reimann, U. Roll, and R. Haas, manuscript in preparation). The extended expression locus codes for a larger pilin which is neither secreted nor assembled into pili (14). Although the biological significance of $\mathrm{L}$ variants is unknown, it is interesting that some $\mathrm{L}$ variants quickly revert to the piliated phenotype. Moreover, $L$ variants show an increased resistance to various hydrophilic antibiotics, such as penicillin and kanamy- 


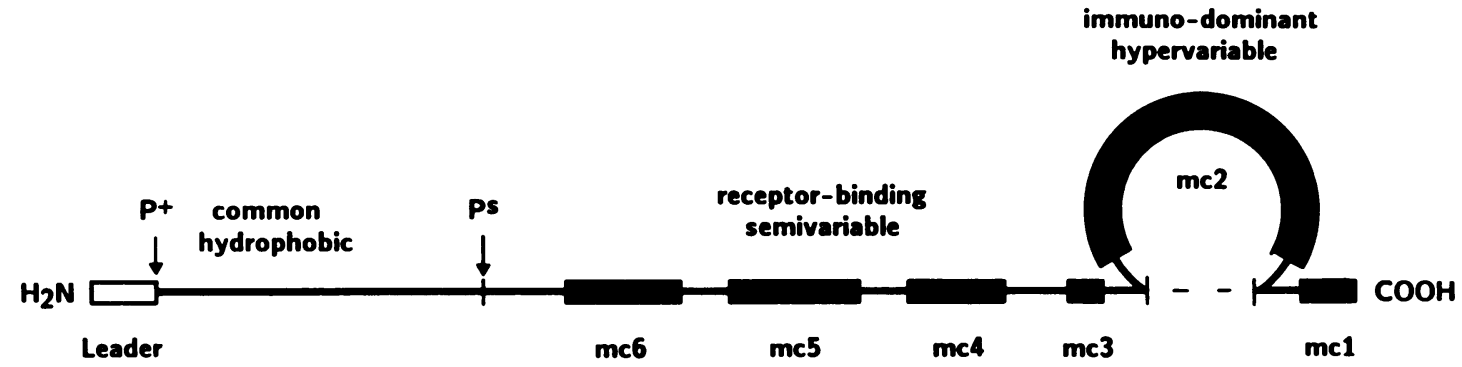

FIG. 1. Primary structure of propilin. Propilin consists of about 160 amino acids plus a seven-amino-acid leader. $\mathrm{P}^{+}$and $\mathrm{P}^{\mathrm{s}}$ denote alternative processing sites of propilin at positions 1 and 40 , respectively. mc1 to mc6 indicate the minicassettes, i.e., the regions which differ in variant pilins and among silent and expressed pilin genes.

cin. It appears that $S$ and $L$ variants account for the majority of nonpiliated phase variants in strain MS11 (14).

\section{Two Mechanisms Account for Pilin Variation}

DNA sequence analysis and Southern hybridizations suggest a common mechanistic basis for the generation of $\mathrm{P}^{+}, \mathrm{S}$, and $\mathrm{L}$ variants (14; Manning et al., in preparation). Koomey et al. demonstrated that recombination in pilE is recA dependent (25). Our own studies with another set of recA mutants extend this observation for $S$ and $L$ variants. Therefore, the increase in kanamycin resistance observed for $L$ variants (see above), which allows direct quantification of transitions to the $\mathrm{L}$ phase, appears to be a suitable tool with which to monitor the frequency of pilin variation in general.

Norlander et al. (34) previously reported a reduction in the frequency of piliation-specific colony morphology changes when cultures are grown in the presence of deoxyribonuclease I (DNase I). Applying L-phase selection, we tested the frequency of phase transitions in the presence or absence of DNase I. The results suggest that in a mid-logarithmicphase culture, the frequency of $\mathrm{P}^{+}$to $\mathrm{L}$-variant transitions is not affected by DNase I; however, in a stationary-phase culture, i.e., when autolysis begins, the frequency of phase transitions eventually rises between 3 - and 100 -fold, and this increase can be abrogated by the addition of DNase I (B. Y. Reimann, R. Haas, and T. F. Meyer, unpublished data). Similar observations have been made by Seifert et al., who used an engineered marker (cat) as a reporter of recombination in pile (46). These authors further demonstrate a substantial decrease in the frequency of phase variation in DNA-uptake-deficient (dud-1) mutants (46). Taking into account two other facts, i.e., the tendency of gonococci to undergo spontaneous autolysis (16) and the high competence (47) of gonococci for transformation by species-specific DNA, it seems evident that pilin antigenic variation is driven by transformation-mediated recombination.

Obviously, Southern hybridizations do not allow a distinction to be made between transformation-mediated recombination and the originally proposed mechanism of pilin variation, gene conversion $(3,13-15,45,54)$. To test whether gene conversion accounts for the low frequency of phase transitions seen in the presence of DNase I or in transformation-defective mutants, we selected $L$ variants during stringent exposure to DNase I. Strikingly, Southern hybridization pattern for $\mathrm{L}$ variants generated under such conditions does not show the usual nonreciprocal (gene conversion-like) recombination. Instead, such variants have undergone reciprocal recombination involving silent and expressed pil genes on the same chromosome (C. P. Gibbs,
B. Y. Reimann, R. Haas, A. Kaufmann, and T. F. Meyer, submitted for publication). On the basis of this observation, we conclude that pilin variation occurs by two distinct recombination processes: (i) transformation-mediated recombination (mimicking gene conversion events), and (ii) reciprocal recombination, which occurs at a lower frequency.

\section{In Vivo Significance of DNA Transformation}

If transformation is an important factor in pilin phase switching, one should assume that nonpiliated revertible gonococcal variants, although believed to be noncompetent (47), are in fact transformation competent with frequencies comparable to that for piliated gonococci. This can be postulated because switching frequencies from the $\mathrm{P}^{+}$to a $\mathbf{P}^{-}$phase are of the same order of magnitude as the reverse transitions. Recent transformation experiments performed with a gonococcal $\operatorname{rec} A$ ::cat construct indeed demonstrate that nonpiliated gonococci that are able to revert, i.e., S- and L-phase variants, are highly competent (Gibbs et al., submitted). However, these observations do not prove that transformation has any in vivo significance. This question seems difficult to address directly, since little is known about the stability of DNA from lysed gonococci or about the growth patterns of gonococci during the course of an infection.

Recent DNA sequencing work performed with iga genes of various gonococci, however, suggests that horizontal genetic transfer might readily occur under natural conditions (R. Halter, J. Pohlner, and T. F. Meyer, submitted for publication). Sequence comparison of four iga genes revealed multiple extended sequence polymorphisms. Some of these polymorphisms are independently conserved in two or three of these iga genes. This reveals a mosaiclike genetic composition, which can be explained by efficient horizontal genetic exchange taking place in individuals infected with more than one strain. The recent identification of a specific DNA sequence involved in gonococcal transformation (10) supports the idea that DNA transformation is an essential factor in genetic exchange in gonococci. Of six DNA uptake sequences identified, one was found to be located in the transcriptional terminator of the iga gene $(10,37)$.

Within the pilEl locus, no such DNA uptake sequence was detected (10). However, transformation-mediated recombination in this locus (and hence pilin variation) might depend on such DNA uptake sequences that may reside in the vicinity of silent pil loci and have thus far escaped our attention. 

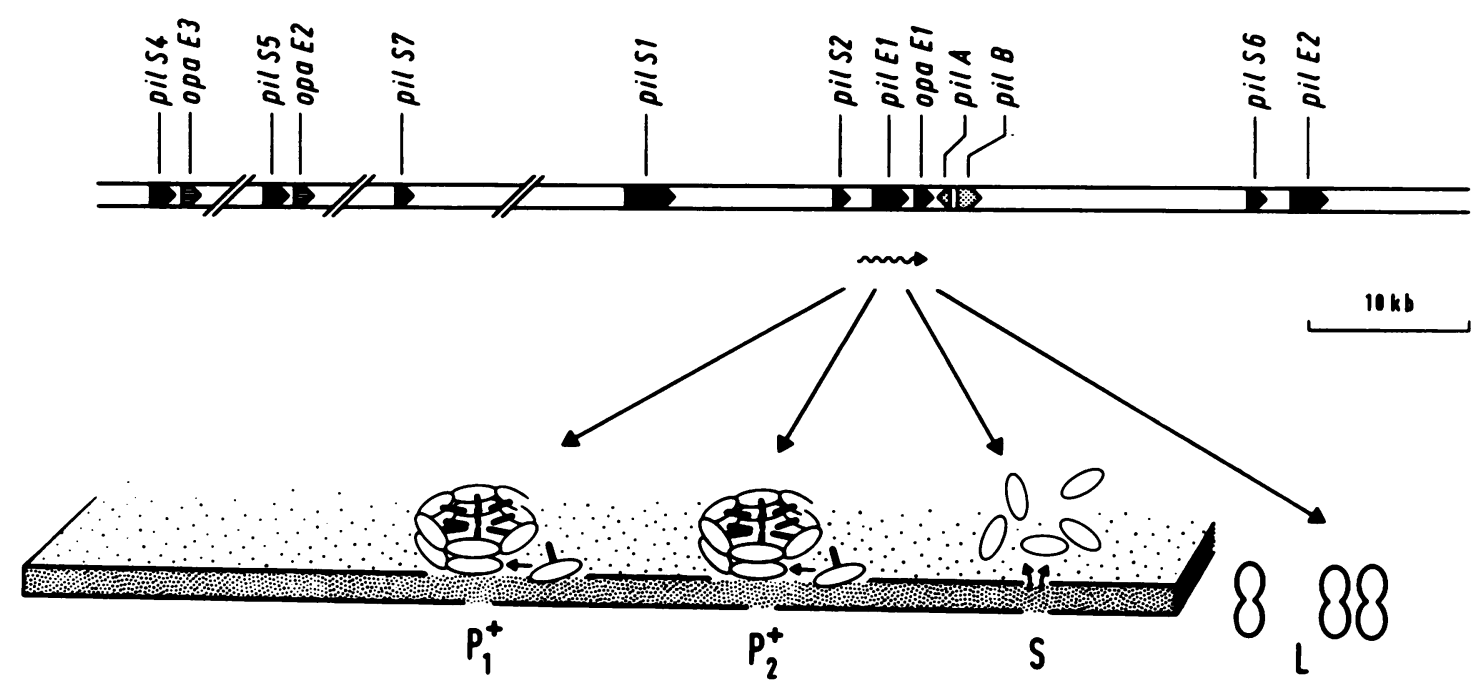

FIG. 2. Organization of pilus gene loci in MS11 and recombination between silent and expression loci. Intragenic recombination in the transcribed pilin gene in pilE leads to variant pilin types, i.e., antigenically variant pilins $\left(P_{1}\right.$ and $\left.P_{2}\right)$, secreted $S$ pilin $(S)$, and $L$ pilin $(L)$, the precise location of which has not been determined. kb, kilobases.

\section{Pilin and Pilus Expression Mutants}

The analysis of pilin variation in gonococci has provided evidence for additional genetic changes, which should be referred to as mutations rather than variations. Two different classes of mutants have been described, deletion mutants and point mutants. Deletion mutants $\left(P_{n}\right)$ have lost the promoter and 5 ' coding sequences of the pilE structural gene $(3,44)$. They show a complete loss of pilin-specific expression at both transcriptional and translational levels. The deletion formation seems to depend on the presence of a functional $r e c A$ gene and is virtually irreversible, providing that there is no second active pilE locus present in the cell (3; P. F. Sparling, personal communication; our unpublished data). If, however, a cell initially possessed two complete expression loci, one of which became deleted, the second locus might eventually be restored by pilE duplication (46), probably via the route of transformation.

The members of the second class of piliation-deficient mutants $\left(\mathrm{P}^{-}\right)$have been characterized as point mutants that can best be isolated from variation-deficient (recA mutant) gonococci (25). Such mutants also revert at low frequencies under $r e c A$ conditions. Point or frameshift mutations have been identified at distinct sites in the pilE gene, giving rise to assembly-deficient, truncated, and/or unstable pilin (25). One might expect, though, that nonpiliated mutants are affected in accessory genes for gonococcal pilus formation (M. Koomey, personal communication).

\section{Regulation of Pilin Expression}

Several lines of evidence suggest that pilE is subject not only to DNA rearrangements that lead to the production of altered pilin, but also to regulatory control mechanisms. Apparent sequence homologies exist in the pilE promoter region with known DNA-binding sites of the Klebsiella ntrA and nifA gene products. By trans-complementation with Klebsiella nifA, activation of pilin expression can be observed in Escherichia coli (H. S. Seifert and M. So, personal communication), suggesting that the pil gene is controlled by an activator, similar to the NifA activator.

Taha et al. have, in fact, described the isolation of two genes from $N$. gonorrhoeae MS11, pilA and pilB, that affect transcription of the pilE gene in trans (56). The two genes are located downstream of the pilEl and opaEl loci (Fig. 2). The pilA product has an activating function and shows at its amino terminus a putative DNA-binding motif. The pilB product acts as a repressor. The two genes, which are arranged in diverging orientations, appear to have overlapping regulatory regions. Since pilA mutants seem to be nonpermissive in gonococci, they are likely to display multiple effects, comparable to pleiotropic virulence regulators described for other systems (see, e.g., reference 30 ).

\section{Organization of opa Genes}

In contrast to the pilin gene system, which includes one or two expression genes and multiple silent partial genes, the opa gene system relies on a gene family consisting only of complete genes, each with a functional promoter $(49,50)$. In $N$. gonorrhoeae, $N$. meningitidis, and $N$. lactamica, 12, 3 or 4 , and 2 opa genes, respectively, have been identified that code for a group of heat-modifiable OPAs (previously referred to as P.II for gonococci or class 5 proteins for meningococci). Most of the opa genes carry variant sequences and appear to be constitutively transcribed $(49,50)$. A genetic linkage exists between some opaE and pil loci (silent as well as expressed), the meaning of which has not been explained (51) (Fig. 2).

Among gonococcal genes that carry a DNA uptake sequence is the opaEl locus (10). This locus was found to undergo recombination with other opa loci $(49,51)$. As in the case of the pilin genes, this process appeared as a nonreciprocal event $(8,49)$; however, in the light of recent findings, it should probably be attributed to transformation-mediated recombination. Recombination between opa genes may occur as an intragenic event, thus giving rise to hybrid genes (8). Although such recombinations can increase the repertoire of a single cell, they do not account for the frequent phase transitions seen for OPA expression in gonococci.

\section{CR Variation: Control of opa Expression}

An intriguing fact is that all opa genes of a cell are transcribed, although not all are translated. This is due to a somewhat peculiar expression control of opa genes, which 


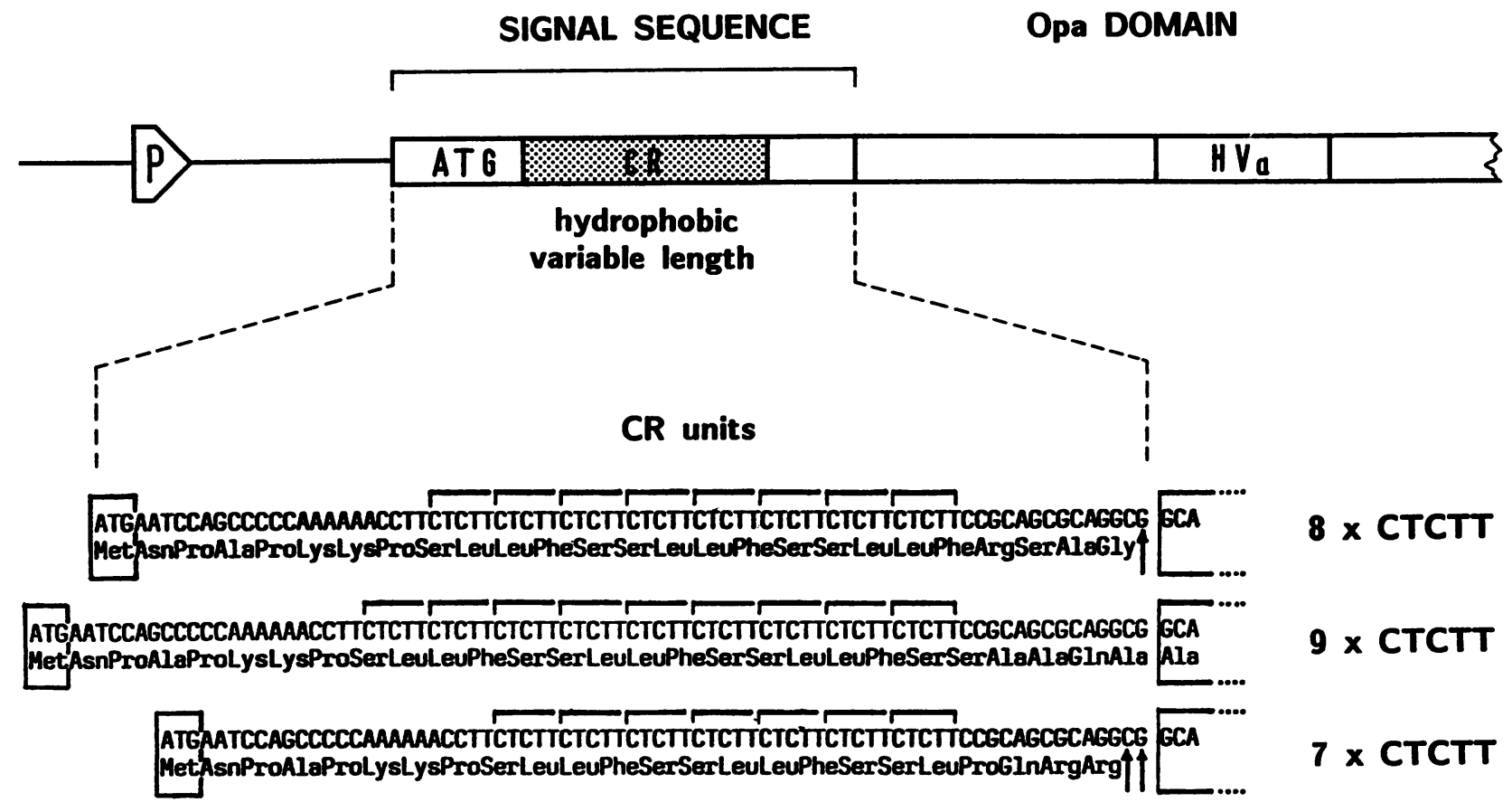

FIG. 3. Location of the coding repeat in the opa genes and the control mechanism of opa gene expression. The number of CR units determines the reading frame of opa genes; if the reading frame is not correct (e.g., eight or nine CR units), no OPA protein will be produced. Changes in the reading frame of opa genes are RecA independent and are thought to be due to replicative slippage.

was found to rely on a repetitive sequence (coding repeat $[C R])$ affecting the translational level $(49,50)$. The CR codes for the hydrophobic core of the leader peptide of OPA proteins and consists of CTCTT pentamer units (Fig. 3). The molecular principle of opa variation is that the number of $\mathrm{CR}$ units (CTCTT) is variable in each of the opa genes and thereby determines the reading frame of an opa gene (49, 50). Depending on the number of $C R$ units (which can range from 7 to 28 , apparently without affecting the export functions of the OPA leader), the expression of each of the opa genes in a cell can be independently switched on and off. Therefore, the basic repertoire of a single cell is limited to the number of genes present. Only occasionally is this relatively limited repertoire of a single cell altered by recombination events between different opa genes, as outlined above $(8,49)$.

Phase transitions in OPA production are generally more frequent than observed for pilin variation, reaching frequencies of several percent per cell per generation. Because of the particular features of the CR region, we have suggested that CR variation occurs by DNA slippage during chromosome duplication $(32,49)$. Recently, we (C. P. Gibbs and T. F. Meyer, unpublished results) and others (J. Swanson, personal communication) have shown that $C R$ variation is independent of RecA. Furthermore, Cannon (personal communication) demonstrated by constructing opa::phoA fusions that $C R$ variation occurs in $E$. coli, suggesting that this process does not need specialized neisserial functions.

\section{BIOLOGICAL SIGNIFICANCE OF ANTIGENIC VARIATION}

\section{Pili}

Several lines of evidence indicate that gonococci undergo pilin variation during a natural infection: (i) gonococcal isolates from sexual partners often differ in pilus type (63); (ii) pili expressed by gonococcal isolates from different anatomical sites have different antigenic properties (59); and (iii) gonococci isolated from a male urethra after challenge with a piliated strain express pili that differ both antigenically and genetically from pili of the inoculated variant (55). Antigenic variation might be necessary to evade the host immune response and/or as a means to adapt to the particular microenvironments of the infected host, such as the recognition of specific receptors on mucosal surfaces. Indeed, there exists cumulative evidence that pili of variants of a single strain differ not only in physical, chemical, and antigenic properties but also in binding characteristics. Isogenic variants of $N$. gonorrhoeae $\mathrm{P} 9$ that produced different pilus types were altered in their ability to adhere to eucaryotic cells. So-called alpha pili bound to human erythrocytes and buccal epithelial cells (28), whereas beta pili preferentially adhered to Chang conjunctiva cells (17). Using isogenic pilin variants of strain MS11, we could show that all piliated variants agglutinated human erythrocytes; some of these variants, however, had lost the ability to adhere to certain epithelial cell lines as well as to cultures of human corneas (58) obtained from different donors. Although all pilin variants produced different pilin types, there was no apparent correlation of the binding capacity with distinct amino acid sequences in the pilin (J. P. M. van Putten, R. Haas, and T. F. Meyer, unpublished data). These observations suggest the existence of different receptors on different human cell types and, furthermore, show that antigenic variation of gonococcal pili is accompanied by changes in the binding characteristics of $N$. gonorrhoeae.

Meningococcal pili also undergo antigenic variation during natural infection. Meningococci isolated from the blood, cerebrospinal fluid, and nasopharynges of individual patients have been found to possess different types of pili (57). 
Unfortunately, it is unknown whether these variants of a single strain differ in their adherence to eucaryotic cells. Meningococcal strains (isolated from carriers as well as symptomatic individuals) have been shown to express pilus types with different morphological, antigenic, and binding properties $(11,41,48,60)$. Therefore, antigenic variation might also have functional consequences for meningococci.

The exact nature of the pilus domain(s) mediating adherence to eucaryotic cells is still undefined. Using a monoclonal antibody against a largely conserved sequence (amino acids 69 to 84) of the pilin molecule (42), Rothbard et al. were able to block the adherence of both the homologous and a heterologous strain of $N$. gonorrhoeae to endometrial carcinoma cells, suggesting that this conserved region contains a common receptor-binding domain (40). This finding, however, has not been confirmed by others. Heckels and Virji found that antibodies recognizing a variable domain of the pilin molecule blocked adhesion to Chang conjunctiva cells, whereas antibodies to a common domain had no effect (19). In this context it should be mentioned that at least one of the cross-reacting antibodies used in this study (SM1) was directed against amino acids 49 to 53 , a conserved sequence (20) that Rothbard et al. had already found not to be involved in adhesion (40). Interestingly, Swanson et al. reported that the conserved sequence from amino acids 69 to 84 was subject to antigenic variation during natural infection (55). This finding suggests that the sequence from amino acids 69 to 84 is not the (only) domain involved in receptor recognition. It has become apparent that in several Gram-negative species, minor pilus-associated proteins, and not the major pilus subunit, are the mediators of adherence and are responsible for tissue tropisms of an infection (see, e.g., references 26 and 29). Whether gonococci possess pilus-associated proteins, their possible role in adherence, and the relationship between the nature of such proteins and antigenic variation are the subjects of intensive research.

\section{OPAs}

The gonococcal OPA (previously P.II) and its OPA counterpart in meningococci (previously class 5 protein) also undergo in vivo antigenic variation during a natural infection. Meningococci isolated from different anatomical sites differ in OPA $(38,57,63)$, and variations in gonococcal OPA expression can be found during the menstrual cycle $(9,23)$. The serological diversity of OPA is relatively limited; gonococci can produce up to seven different OPAs (43), whereas clinical meningococcal isolates originating from a single clone and obtained over a 4-year period have been shown to produce no more than eight different OPAs (1). The biological significance of the variation of OPA expression is still uncertain, although there is evidence that it plays a role in the modulation of adhesive properties of the bacteria. Certain OPAs have been associated with an increased adherence of the bacteria to certain types of epithelial cells, whereas other OPA variants can be associated with the binding to leukocytes $(17,22,24,27,61 ;$ J. P. M. van Putten and T. F. Meyer, unpublished results). In addition, gonococcal OPAs that are associated with pronounced colony opacity function as intergonococcal clumping factors (or adhesins) in that they bind to the oligosaccharide part of the lipopolysaccharide of neighboring gonococci $(5,53)$. Evasion of the host immune defense is, considering the limited repertoire of the variation, probably not the main function of the OPA variation; the variability may rather occur as a response to other stimuli during the course of an infection.
Whether the variability of OPA expression also plays a role in the process after cellular attachment remains to be seen. Immunoelectron microscopy studies indicate that there is no alteration in OPA expression during the adherence and internalization of gonococci into Chang conjunctiva cells (J. F. L. Weel and J. P. M. van Putten, unpublished data).

\section{Identification of Host Cell Receptors}

Conclusions drawn from numerous in vivo and in vitro experiments on the binding of neisseriae to different cell types suggest a difference in the density and/or molecular structure of receptor molecules in various tissues $(19,22,27$, $28,40-42,48,57,58,60,61)$. This diversity in receptor molecules might explain the need for bacteria to produce adhesins, such as pili and OPA, with variable binding specificities. Increasing effort has been made to identify host cell receptors involved in the bacterium-host cell interaction $(4,7,12,18,52,62)$. However, in terms of the relationship between antigenic variation, variable binding properties, and the apparent existence of more than a single type of receptor in host tissues, much work remains to be done. The establishment of suitable cell culture systems, the mutagenesis of adhesive properties of $N$. gonorrhoeae and $N$. meningitidis, and the isolation of glycolipids and (glyco)proteins from the membranes of target cells, as well as other strategies, might help to increase our understanding at this point.

\section{ACKNOWLEDGMENTS}

We thank Carol Gibbs for carefully reading the manuscript. We gratefully acknowledge the communication of unpublished information by our colleagues as cited in the text.

\section{LITERATURE CITED}

1. Achtmann, M., M. Neibert, B. A. Crowe, W. Strittmacher, B. Kusecek, E. Weyse, M. J. Walsh, B. Slawig, G. Morelli, A. Moll, and M. S. Blake. 1988. Purification and characterization of eight class 5 outer membrane protein variants from a clone of Neisseria meningitidis serogroup A. J. Exp. Med. 168:507-525

2. Barbour, A. G. 1985. Clonal polymorphism of surface antigens in a relapsing fever Borrelia species, p. 235-245. In G. G. Jackson and $\mathrm{H}$. Thomas (ed.), The pathogenesis of bacterial infections. Springer-Verlag KG, Berlin.

3. Bergström, S., K. Robbins, J. M. Koomey, and J. Swanson. 1986. Piliation control mechanisms in Neisseria gonorrhoeae. Proc. Natl. Acad. Sci. USA 83:3890-3894.

4. Bessen, D., and E. C. Gotschlich. 1987. Chemical characterization of binding properties of opacity-associated protein II from Neisseria gonorrhoeae. Infect. Immun. 55:141-147.

5. Blake, M. S. 1985. Functions of the outer membrane proteins of Neisseria gonorrhoeae, p. 51-66. In G. G. Jackson and H. Thomas (ed.), The pathogenesis of bacterial infections. Springer-Verlag KG, Berlin.

6. Borst, P., and G. A. M. Cross. 1982. Molecular basis for trypanosome antigenic variation. Cell 29:291-298.

7. Buchanan, T. M., W. A. Pearce, and K. C. S. Chen. 1978 Attachment of Neisseria gonorrhoeae pili to human cells and investigations of the chemical nature of the receptor for gonococcal pili, p. 242-249. In G. F. Brooks, E. C. Gotschlich, K. K. Holmes, W. D. Sawyer, and F. E. Young (ed.), Immunobiology of Neisseria gonorrhoeae. American Society for Microbiology, Washington, D.C.

8. Connell, T. D., W. J. Black, T. H. Kawula, D. S. Barritt, J. A. Dempsey, K. Kverneland, Jr., A. Stephenson, B. S. Schepart, G. L. Murphy, and J. G. Cannon. 1988. Recombination among protein II genes of Neisseria gonorrhoeae generates new coding sequences and increases structural variability in the protein II family. Mol. Microbiol. 2:227-236. 
9. Draper, D. L., J. F. James, G. F. Brooks, and R. L. Sweet. 1980. Comparison of virulence markers of peritoneal and fallopian tube isolates with endocervical Neisseria gonorrhoeae isolates from women with salpingitis. Infect. Immun. 27:882-888.

10. Goodman, S. D., and J. J. Scocca. 1988. Identification and arrangement of the DNA sequence recognized in specific transformation of Neisseria gonorrhoeae. Proc. Natl. Acad. Sci. USA 85:6982-6986.

11. Greenblatt, J. J., K. Floyd, M. E. Phillips, and C. E. Frasch. 1988. Morphological differences in Neisseria meningitidis pili. Infect. Immun. 56:2356-2362.

12. Gubish, E. R., K. C. S. Chen, and T. M. Buchanan. 1982. Attachment of gonococcal pili to lectin-resistant clones of Chinese hamster ovary cells. Infect. Immun. 37:189-194.

13. Haas, R., and T. F. Meyer. 1986. The repertoire of silent pilus genes in Neisseria gonorrhoeae: evidence for gene conversion. Cell 44:107-115.

14. Haas, R., H. Schwarz, and T. F. Meyer. 1987. Release of soluble pilin antigen coupled with gene conversion in Neisseria gonorrhoeae. Proc. Natl. Acad. Sci. USA 84:9079-9083.

15. Hagblom, P., E. Segal, E. Billyard, and M. So. 1985. Intragenic recombination leads to pilus antigenic variation in Neisseria gonorrhoeae. Nature (London) 315:156-158.

16. Hebeler, B. H., and F. E. Young. 1975. Autolysis of Neisseria gonorrhoeae. J. Bacteriol. 122:385-392.

17. Heckels, J. E. 1982. Role of surface proteins in the adhesion of Neisseria gonorrhoeae, p. 301-304. In D. Schlessinger (ed.), Microbiology-1982. American Society for Microbiology, Washington, D.C.

18. Heckels, J. E., and L. T. James. 1980. The structural organization of the gonococcal cell envelope and its influence on pathogenesis, p. 25-28. In D. Danielsson and S. Normark (ed.), Genetics and immunobiology of pathogenic Neisseria. University of Umeå, Umeå, Sweden.

19. Heckels, J. E., and M. Virji. 1985. Antigenic variation of gonococcal pili: immunochemical and biological studies, p. 288-296. In G. K. Schoolnik, G. F. Brooks, S. Falkow, C. E. Frasch, J. S. Knapp, J. A. McCutchan, and S. A. Morse (ed.), The pathogenic neisseriae. American Society for Microbiology, Washington, D.C.

20. Heckels, J. E., and M. Virji. 1986. Antigenic variation of gonococcal surface proteins: effect on virulence, p. 89-94. In D. L. Lark (ed.), Protein-carbohydrate interactions in biological systems. Academic Press, Inc. (London), Ltd., London.

21. Hermodson, M. A., K. C. S. Chen, and T. M. Buchanan. 1978. Neisseria pili proteins: amino-terminal amino acid sequences and identification of an unusual amino acid. Biochemistry 17:442-445.

22. James, J. F., C. J. Lammel, D. L. Draper, and G. F. Brooks. 1980. Attachment of Neisseria gonorrhoeae to eukaryotic cells and tissues, p. 213-216. In D. Danielsson and S. Normark (ed.), Genetics and immunobiology of pathogenic Neisseria. University of Umeå, Umeå, Sweden.

23. James, J. F., and J. Swanson. 1978. Studies on gonococcus infection. XIII. Occurrence of color/opacity colonial variants in clinical cultures. Infect. Immun. 19:332-340.

24. King, G. J., and J. Swanson. 1978. Studies on gonococcus infection. XV. Identification of surface proteins of Neisseria gonorrhoeae correlated with leukocyte association. Infect. Immun. 21:575-584.

25. Koomey, J. M., E. C. Gotschlich, K. Robbins, S. Bergström, and J. Swanson. 1987. Effects of recA mutations on pilus antigenic variation and phase transitions in Neisseria gonorrhoeae. Genetics 117:391-398.

26. Korhonen, T. K., R. Virkola, B. Westerlund, A. M. Tarkkanen, K. Lähteenmäki, T. Sareneva, J. Parkkinen, P. Kuusela, and H. Holthöfer. 1988. Tissue interactions of Escherichia coli adhesins. Antonie van Leeuwenhoek. J. Microbiol. 54:411-420.

27. Lambden, P. R., J. E. Heckels, L. T. James, and P. J. Watts. 1979. Variations in surface protein composition associated with virulence properties in opacity types of Neisseria gonorrhoeae. J. Gen. Microbiol. 114:305-312.

28. Lambden,' P. R., J. N. Robertson, and P. J. Watt. 1980.
Biological properties of two distinct pilus types produced by isogenic variants of Neisseria gonorrhoeae P9. J. Bacteriol. 141:393-396.

29. Lindberg, F., B. Lund, L. Johansson, and S. Normark. 1987. Localisation of the receptor-binding protein at the tip of the bacterial pilus. Nature (London) 328:84-87.

30. Mekalanos, J. J., K. M. Peterson, T. Finn, and S. Knapp. 1988. The pathogenesis and immunology of Vibrio cholerae and Bordetella pertussis. Antonie van Leeuwenhoek J. Microbiol. 54:379-387.

31. Meyer, T. F., E. Billyard, R. Haas, S. Störzbach, and M. So. 1984. Pilus gene of Neisseria gonorrheae: chromosomal organization and DNA sequence. Proc. Natl. Acad. Sci. USA 81: 6110-6114.

32. Meyer, T. F., and R. Haas. 1988. Phase and antigenic variation by DNA rearrangements in procaryotes. Symp. Soc. Gen. Microbiol. 43:193-219.

33. Meyer, T. F., N. Mlawer, and M. So. 1982 . Pilus expression in Neisseria gonorrhoeae involves chromosomal rearrangement. Cell 30:45-52.

34. Norlander, L., J. Davies, A. Norquist, and S. Normark. 1979. Genetic basis for colonial variation in Neisseria gonorrhoeae. $\mathrm{J}$. Bacteriol. 138:762-769.

35. Perry, A. C. F., I. J. Nicolson, and J. R. Saunders. 1987. Structural analysis of the pilE region of Neisseria gonorrhoeae P9. Gene 60:85-92.

36. Perry, A. C. F., I. J. Nicolson, and J. R. Saunders. 1988. Neisseria meningitidis $\mathrm{C} 114$ contains silent, truncated pilin genes that are homologous to Neisseria gonorrhoeae pil sequences. J. Bacteriol. 170:1691-1697.

37. Pohlner, J., R. Halter, K. Beyreuther, and T. F. Meyer. 1987. Gene structure and extracellular secretion of Neisseria gonorrhoeae IgA protease. Nature (London) 325:458-462.

38. Poolman, J. T:, S. DeMarie, and H. C. Zanen. 1980. Variability of low-molecular-weight, heat-modifiable outer membrane proteins of Neisseria meningitidis. Infect. Immun. 30:642-648.

39. Potts, W. J., and J. R. Saunders. 1988. Nucleotide sequence of the structural gene for class I pilin from Neisseria meningitidis: homologies with the pilE locus of Neisseria gonorrhoeae. Mol. Microbiol. 2:647-653.

40. Rothbard, J. B., R. Fernandez, L. Wang, N. N. H. Teng, and G. K. Schoolnik. 1985. Antibodies to peptides corresponding to a conserved sequence of gonococcal pilins block bacterial adhesion. Proc. Natl. Acad. Sci. USA 82:915-919.

41. Salit, I. E., and G. Morton. 1981. Adherence of Neisseria meningitidis to human epithelial cells. Infect. Immun. 31:430435.

42. Schoolnik, G. K., R. Fernandez, J. Y. Tai, J. Rothbard, and E. C. Gotschlich. 1984. Gonococcal pili. Primary structure and receptor binding domain. J. Exp. Med. 159:351-370.

43. Schwalbe, R. S., P. F. Sparling, and J. G. Cannon. 1985. Variation of Neisseria gonorrhoeae protein II among isolates from an outbreak caused by a single gonococcal strain. Infect. Immun. 49:250-252.

44. Segal, E., E. Billyard, M. So, S. Störzbach, and T. F. Meyer. 1985. Role of chromosomal rearrangements in $N$. gonorrhoeae pilus phase variation. Cell 40:293-300.

45. Segal, E., P. Hagblom, H. S. Seifert, and M. So. 1986. Antigenic variation of gonococcal pilus involves assembly of separated silent gene segments. Proc. Natl. Acad. Sci. USA 83:2177-2181.

46. Seifert, H. S., R. S. Ajioka, C. Marchal, P. F. Sparling, and M. So. 1988. DNA transformation leads to pilin antigenic variation in Neisseria gonorrhoeae. Nature (London) 336:392-395.

47. Sparling, P. F. 1966. Genetic transformation of Neisseria gonorrhoeae to streptomycin resistance. J. Bacteriol. 92:1364-1370.

48. Stephens, D. S., L. H. Hoffman, and Z. A. McGee. 1983. Interaction of Neisseria meningitidis with human nasopharyngeal mucosa: attachment and entry into columnar epithelial cells. J. Infect. Dis. 148:369-376.

49. Stern, A., M. Brown, P. Nickel, and T. F. Meyer. 1986. Opacity genes in Neisseria gonorrhoeae: control of phase and antigenic variation. Cell 47:61-71.

50. Stern, A., and T. F. Meyer. 1987. Common mechanism control- 
ling phase and antigenic variation in pathogenic. Neisseriae. Mol. Microbiol. 1:5-12.

51. Stern, A., P. Nickel, T. F. Meyer, and M. So. 1984. Opacity determinants of Neisseria gonorrhoeae: gene expression and chromosomal linkage to the gonococcal pilus gene. Cell 37: $447-456$.

52. Strömberg, N., C. Deal, G. Nyberg, S. Normark, M. So, and K. A. Karlsson. 1988. Identification of carbohydrate structures which are possible receptors for Neisseria gonorrhoeae. Proc. Natl. Acad. Sci. USA 85:4902-4907.

53. Swanson, J. 1978. Studies on gonococcus infection. XIV. Cell wall protein differences among color/opacity variants of Neisseria gonorrhoeae. Infect. Immun. 21:292-302.

54. Swanson, J., S. Bergström, K. Robbins, O. Barrera, D. Corwin, and J. M. Koomey. 1986. Gene conversion involving the pilin structural gene correlates with pilus ${ }^{+}$pilus $^{-}$changes in Neisseria gonorrhoeae. Cell 47:267-276.

55. Swanson, J., K. Robbins, O. Barrera, D. Corwin, J. Boslego, J. Ciak, M. Blake, and J. M. Koomey. 1987. Gonococcal pilin variants in experimental gonorrhoeae. J. Exp. Med. 165:1344 1357.

56. Taha, M. K., M. So, E. Billyard, and C. Marchal. 1988. Pilin expression in Neisseria gonorrhoeae is under both positive and negative transcriptional control. EMBO J. 7:4367-4378.

57. Tinsley, C. R., and J. E. Heckels. 1986. Variation in the expression of pili and outer membrane protein by Neisseria meningitidis during the course of meningococcal infection. $J$. Gen. Microbiol. 132:2483-2490.

58. Tjia, K. F., J. P. M. van Putten, E. Pels, and H. C. Zanen. 1988. The interaction between Neisseria gonorrhoeae and the human cornea in organ culture. Graefe's Arch. Clin. Exp. Opthalmol. 226:341-345.

59. Tramont, E. C., W. C. Hodge, M. J. Gilbreath, and J. Ciak. 1979. Differences in attachment antigens of gonococci in reinfection. J. Lab. Clin. Med. 93:730-735.

60. Trust, T. J., R. M. Gillespie, A. R. Bhatti, and L. A. White. 1983. Differences in the adhesive properties of Neisseria meningitidis for human buccal epithelial cells and erythrocytes. Infect. Immui.. 41:106-113.

61. Virji, M., and J. E. Heckels. 1986. The effect of protein II and pili on the interaction of Neisseria gonorrhoeae with human polymorphonuclear leucocytes. J. Gen. Microbiol. 132:503-512.

62. Wiseman, G. M., and P. McNicol. 1973. The nature of human erythrocyte receptors for Neisseria gonorrhoeae. Can. J. Microbiol. 28:219-222.

63. Zak, K., J. L. Diaz, D. Jackson, and J. E. Heckels. 1984. Antigenic variation during infection with Neisseria gonorrhoe$a e$ : detection of antibodies to surface proteins in sera of patients with gonorrhea. J. Infect. Dis. 149:166-174. 